\title{
Pioglitazone Adjunctive Therapy for Moderate-to-Severe Major Depressive Disorder: Randomized Double-Blind Placebo-Controlled Trial
}

\author{
Khatereh Sepanjnia', Amirhossein Modabbernia', Mandana Ashrafi', Mohammad-Jafar Modabbernia ${ }^{2}$ and \\ Shahin Akhondzadeh*,I \\ 'Psychiatric Research Centre, Roozbeh Psychiatric Hospital, Tehran University of Medical Sciences, Tehran, Iran; ${ }^{2}$ Department of Psychiatry, \\ Guilan University of Medical Sciences, Guilan, Iran
}

\begin{abstract}
Thiazolidinediones have shown antidepressant effect in animal studies, as well as in some uncontrolled studies evaluating human subjects with concurrent major depressive disorder (MDD) and metabolic syndrome. Although these drugs are insulin sensitizers, they also have important anti-inflammatory, neuroprotective, and anti-excitotoxic properties. Thus, we hypothesized that they would show antidepressant effect in patients with MDD even if it was not accompanied by metabolic disturbances. In this double-blind placebocontrolled study, 40 patients with MDD (DSM-IV-TR) and Hamilton depression rating scale- 17 (Ham-D) score $\geqslant 22$ were randomized to citalopram plus pioglitazone ( $15 \mathrm{mg}$ every $12 \mathrm{~h})(n=20)$ or citalopram plus placebo $(n=20)$ for 6 weeks. Patients were evaluated using Ham-D (weeks $0,2,4,6$ ). Repeated-measure analysis of variance (ANOVA) and analysis of covariance were used for comparison of scores between the two groups. Treatment response ( $\geqslant 50 \%$ reduction in Ham-D score), remission (Ham-D score $\leqslant 7$ ), and early improvement ( $\geqslant 20 \%$ reduction in Ham-D score within the first 2 weeks) were compared between the two groups using Fisher's exact test. Pioglitazone showed superiority over placebo during the course of the trial $(F(I, 38)=9.483, p=0.004)$. Patients in the pioglitazone group had significantly lower scores at all time points than the placebo group $(P<0.0 \mathrm{I})$. Frequency of early improvement, response (week 6), and remission was significantly higher in the pioglitazone group (95\%, 95\%, 45\%, respectively) than in the placebo (30\%, $40 \%$, $15 \%$ respectively) group $(P<0.001,<0.001,0.04$, respectively). Frequency of side effects was similar between the two groups. Pioglitazone is a safe and effective adjunctive short-term treatment in patients with moderate-to-severe MDD even in the absence of metabolic syndrome and diabetes (http://clinicaltrials.gov/ct2/show/NCT0I I09030).

Neuropsychopharmacology (2012) 37, 2093-2I00; doi:I0. I038/npp.2012.58; published online 2 May 2012
\end{abstract}

Keywords: PPAR-gamma; pioglitazone; major depressive disorder; adjunctive therapy; thiazolidinedione; randomized controlled trial

\section{INTRODUCTION}

Despite the advent of several antidepressant medications, the treatment of major depressive disorder (MDD) is still far from optimal (Warden et al, 2007). A large proportion of patients with MDD do not respond to their first medication (Trivedi et al, 2006b; Warden et al, 2007; Schatzberg, 2008). To achieve favorable response, these patients are generally treated by either switching to another treatment or with augmentation therapy. Recently, combination therapy from the beginning of treatment has been suggested to achieve higher responses and remission rates (Blier et al, 2010;

*Correspondence: Professor S Akhondzadeh, Psychiatric Research Center, Roozbeh Psychiatric Hospital, Tehran University of Medical Sciences, South Kargar Street, Tehran 13337, Iran, Tel: + I 9821 88281866, Fax: + | 98 21 55419|13, E-mail: s.akhond@neda.net The abstract of this work was submitted to CINP 2012.

Received 31 January 2012; revised 5 March 2012; accepted 26 March 2012
Nelson et al, 2004; Blier et al, 2009), although not all studies (Rush et al, 2011) have supported this notion. In the recent decade, several augmentative strategies for treatment of MDD have been developed. Some of these treatment modalities focus on recently developed hypotheses of pathophysiological processes in patients with MDD (Akhondzadeh et al, 2009; Muller et al, 2006; Abolfazli et al, 2011). These mainly include immune system dysfunction, hypothalamic-pituitaryadrenal (HPA) axis and metabolic derangements, impaired neuroprotection, or neuroinflammation (Akhondzadeh et al, 2009; Fava and Rush, 2006).

The peroxisome proliferator-activated nuclear receptor (PPAR)-gamma is a member of the nuclear receptor family of transcription factors. The synthetic agonists of this receptor (troglitazone, rosiglitazone, or pioglitazone) known as thiazolidinediones (TZD) are primarily used as antidiabetic drugs (Spiegelman, 1998). PPAR-gamma has important anti-inflammatory, neuroprotective, antioxidative, and anti-excitotoxic properties (Garcia-Bueno et al, 
2010; Jeong et al, 2011). The activation of PPAR-gamma by its natural (15d-PGJ2) or synthetic ligands is associated with an increase in neurotrophic factors (Toyomoto et al, 2004; Garcia-Bueno et al, 2005). The activation of this receptor also protects neurons from disruption of glucose and glutamate metabolism following stress exposure, which has an important association with MDD (Garcia-Bueno et al, 2007).

Several studies have addressed the role of PPAR-gamma agonists in the treatment of neuropsychiatric diseases including Alzheimer's disease and multiple sclerosis (Miller et al, 2011; Kaiser et al, 2009). Studies on animal model of MDD have shown beneficial effect of PPAR-gamma agonists in the treatment of MDD (Sadaghiani et al, 2011; Budni et al, 2011; Eissa Ahmed and Al-Rasheed, 2009; Rosa et al, 2008). In a case report in 2009, Kemp and colleagues reported a patient with concomitant metabolic syndrome and resistant MDD whose depressive symptoms responded markedly to pioglitazone (Kemp et al, 2009). Subsequently, two other uncontrolled pilot studies have addressed beneficial roles of these drugs in patients with concomitant MDD and metabolic syndrome (Kemp et al, 2012; Rasgon et al, 2010). However, as mentioned above, PPAR-gamma agonists exert their effect on the brain with a wide variety of mechanisms, most of which are not directly related to their 'insulin-sensitizing' effect. Furthermore, because these drugs are not associated with the risk of hypoglycemia or significant cardiac side effects in healthy individuals, they might be good augmentation candidates in moderate-to-severe MDD.

Thus, we hypothesized that pioglitazone would show an antidepressant effect even in depressed patients without significant metabolic problems. In the present double-blind placebo-controlled study, we aimed to evaluate the adjunctive effect of pioglitazone to citalopram in the treatment of patients with moderate-to-severe MDD who did not have significant metabolic problems.

\section{PATIENTS AND METHODS}

\section{Trial Design}

This was a single-center, randomized, double-blind, placebocontrolled, parallel-group study conducted in Tehran, Iran.

\section{Participants}

Eligible patients were individuals 18 to 50 years of age with diagnosis of MDD based on DSM-IV-TR criteria, Hamilton Depression Rating Scale-17 items (Ham-D) score of $\geqslant 22$, and a score of 2 or more on item 1 of Ham-D. All patients and their legally authorized representatives had to sign a written informed consent to be eligible for the study. All patients were told that they could withdraw from the study at any time. Citalopram had to be the drug of choice for the patients regardless of other eligibility criteria. The protocol was approved by the Institutional Review Board (IRB) of Tehran University of Medical Sciences (Grant No: 9476). The study was conducted in agreement with the Declaration of Helsinki.

Patients with psychosis, problems in other DSM Axes or other types of affective disorders, eating disorders, current anxiety disorders (excluding specific phobia), substance abuse or dependence in the past 3 months, patients whose score on the suicide item of the Ham-D was more than two, or those who were judged to have substantial risk of suicide by the physician were excluded from the study. In addition, all patients who took other psychotropic (including antidepressant) agents in the past 4 weeks or electroconvulsive therapy in the past 2 months were excluded. Furthermore, pregnant and lactating women, patients with serious or life-threatening disease, those who fulfilled the criteria for metabolic syndrome, and patients with drug- or insulin-dependent diabetes, liver disease, or congestive heart failure (New York Heart Association Class III and IV) were not eligible for the study. All screened patients underwent a thorough clinical, electrocardiographic, and laboratory examination to test for the presence of diabetes, metabolic syndrome, liver disease, and heart problems. Metabolic syndrome was diagnosed using Adult Treatment Panel (ATP)-III criteria: the presence of any three of the following five traits: waist circumference in men $>102 \mathrm{~cm}$ and in women $>88 \mathrm{~cm}$, serum triglycerides $\geqslant 150 \mathrm{mg} / \mathrm{dl}$ or drug treatment for hypertriglyceridemia, serum HDL cholesterol $<40 \mathrm{mg} / \mathrm{dl}$ in men and $<50 \mathrm{mg} / \mathrm{dl}$ in women or drug treatment for low HDL, blood pressure $\geqslant 130 / 85 \mathrm{~mm} \mathrm{Hg}$ or drug treatment for elevated blood pressure, and fasting plasma glucose $\geqslant 100 \mathrm{mg} / \mathrm{dl}$ or drug treatment for elevated blood glucose.

\section{Changes to Trial Design}

There was an important change to the originally published protocol, which was amended at the beginning of the study. This was omission of a visit at the end of the first week to decrease the total number of visits and to increase the feasibility of the trial.

\section{Study Settings}

The study was conducted at an outpatient clinic of the Roozbeh Psychiatric Hospital, a tertiary psychiatric referral center affiliated with Tehran University of Medical Sciences, Tehran, Iran, from April 2010 to April 2011.

\section{Interventions}

The patients were randomly assigned to receive either pioglitazone (Actos, Eli Lilly, Indianapolis, USA) $15 \mathrm{mg}$ every $12 \mathrm{~h}$ or placebo (with the same shape, color, and taste as pioglitazone) every $12 \mathrm{~h}$ for six consecutive weeks. All patients received citalopram $20 \mathrm{mg} /$ day for the first week followed by $30 \mathrm{mg} /$ day for subsequent 5 weeks. In addition, all patients who had sleep disturbances received $10 \mathrm{mg}$ chlordiazepoxide each night for the first week.

\section{Outcomes}

The main outcome of the study was the Ham-D score, which was measured at baseline, second, fourth, and sixth weeks. The primary outcome measure was the difference of Ham-D score at the end of sixth week between pioglitazone and placebo group after controlling for baseline Ham-D scores. We also compared the score changes in four visits: early improvement (at least 20\% reduction in Ham-D score in the 
first two weeks), score reduction, response rates (at least $50 \%$ decrease in the Ham-D score), and remission rates (Ham-D score $\leqslant 7$ ) at the end of trial between the two groups. Moreover, we compared the score changes in the first 2 weeks and after the first 2 weeks between the two groups. All patients were systematically asked for adverse events in the second, fourth, and sixth week of the trial. Adverse event recording was augmented by self-report from the patients.

\section{Sample Size}

Using a power of $80 \%$ and two-sided significance of $5 \%$ with a SD of four on the Ham-D scale (based on a previous study by our group), and assuming a clinically significant difference of four on the scale, we calculated a sample size of 34 . Assuming a $15 \%$ attrition rate, a final sample size of 40 subjects was calculated; the patients were anticipated to be recruited within 1 year.

\section{Randomization, Allocation Concealment, and Blinding}

By using a computerized random number generator, study subjects were randomized in a $1: 1$ ratio in blocks of four to receive either pioglitazone or placebo in addition to their standard treatment. Allocation concealment was done using sequentially numbered, sealed, opaque, and stapled envelopes. Separate persons were responsible for randomization and allocation, as well as interviewing. The physician who referred the patient, the patients, the resident who administered the drugs and rated the patients, and the statistician were blinded to allocation.

\section{Statistical Analysis}

IBM SPSS Statistic 19.0.0 (IBM Corporation) was used to analyze the data. We reported continuous variables as mean $( \pm S D)$ and categorical variables as number (percentage) unless stated otherwise. Analysis of covariance (ANCOVA), controlling for the baseline score, was used to compare the end-point score on Ham-D between placebo and pioglitazone groups. Two-factor analysis of variance (ANOVA) with repeated measures was used to compare the score change between the two groups (group as between-subject factor) with four measurements as within-subject factor. In repeated-measure testing, whenever Mauchly's test of sphericity was significant, we used Greenhouse-Geisser correction for degrees of freedom. ANCOVA was used to compare the scores at each time point, as well as the score changes between the groups. We calculated Cohen's $d$ effect sizes by dividing the mean difference of score change in the two groups by their pooled SD at each time point. Fisher's exact test was used for comparison of proportions (including frequency of side effects, percentage of responders, early improvers, and patients with complete remission) between the two groups. In addition, risk ratios with $95 \%$ confidence intervals were reported for categorical outcomes. A $p$-value of $<0.05$ was considered statistically significant.

\section{RESULTS}

\section{Participants}

After screening 64 patients for selection criteria, 40 eligible patients were assigned to either pioglitazone plus citalopram $(n=20)$ or placebo plus citalopram $(n=20)$. Table 1 shows baseline data of the patients. There were no dropouts or reports of serious adverse events during the course of the study. Three patients in the pioglitazone group and four patients in the placebo group received $10 \mathrm{mg}$ chlordiazepoxide for 1 week. All patients entered analysis with their complete data. Baseline Ham-D scores were not different between the two groups (mean \pm SD for pioglitazone $=$ $25.6 \pm 3.7$, for placebo $=25.1 \pm 3.2, p=0.685)$.

\section{Analysis of Outcomes}

ANCOVA with control for baseline Ham-D scores showed significantly lower scores in the pioglitazone group than in the placebo group at the second, fourth, and sixth week

Table I Baseline Characteristics of the Patients

\begin{tabular}{|c|c|c|}
\hline Variable & $\begin{array}{l}\text { Pioglitazone group } \\
\qquad(n=20)\end{array}$ & $\begin{array}{l}\text { Placebo group } \\
(n=20)\end{array}$ \\
\hline Age, years, mean $\pm S D$ & $31.4 \pm 5.4$ & $32.7 \pm 5.4$ \\
\hline Sex, female, $n(\%)$ & $14(70 \%)$ & $15(75 \%)$ \\
\hline Married, n (\%) & $8(40 \%)$ & $8(40 \%)$ \\
\hline $\begin{array}{l}\text { University education, } \\
n(\%)\end{array}$ & $6(30 \%)$ & $7(35 \%)$ \\
\hline $\begin{array}{l}\text { Number of previous } \\
\text { episodes, mean } \pm \text { SD }\end{array}$ & $3.6 \pm 0.8$ & $3.5 \pm 0.8$ \\
\hline $\begin{array}{l}\text { Drugs used in last } \\
\text { episode, } n(\%)\end{array}$ & $\begin{array}{l}\text { Fluoxetine: } 12 \text { (60\%); } \\
\text { Venlafaxine: } 4 \text { (20\%); } \\
\text { Sertraline: } 4 \text { (20\%) }\end{array}$ & $\begin{array}{l}\text { Fluoxetine: I0 (50\%); } \\
\text { Venlafaxine: } 5 \text { (25\%); } \\
\text { Sertraline: } 5(25 \%)\end{array}$ \\
\hline $\begin{array}{l}\text { Baseline weight, kg, } \\
\text { mean } \pm \mathrm{SD}\end{array}$ & $70.3 \pm 7.8$ & $68.7 \pm 9.5$ \\
\hline $\begin{array}{l}\text { Body mass index, } \\
\mathrm{kg} / \mathrm{m}^{2}, \text { mean } \pm \mathrm{SD}\end{array}$ & $23.97 \pm 3.67$ & $22.64 \pm 3.30$ \\
\hline $\begin{array}{l}\text { Systolic blood } \\
\text { pressure, } \mathrm{mm} \mathrm{Hg} \text {, } \\
\text { mean } \pm \mathrm{SD}\end{array}$ & $124 \pm 34$ & $128 \pm 30$ \\
\hline $\begin{array}{l}\text { Baseline Hamilton } \\
\text { Depression rating scale } \\
\text { score, mean } \pm \mathrm{SD}\end{array}$ & $25.6 \pm 3.7$ & $25.1 \pm 3.2$ \\
\hline $\begin{array}{l}\text { Fasting blood glucose, } \\
\mathrm{mg} / \mathrm{dl} \text {, mean } \pm \mathrm{SD}\end{array}$ & $87.9 \pm 12.9$ & $90.2 \pm 11.1$ \\
\hline $\begin{array}{l}\text { Fasting plasma insulin, } \\
\mu \bigcup / m l \text {, mean } \pm \mathrm{SD}\end{array}$ & $6.6 \pm 2.5$ & $6.8 \pm 2.9$ \\
\hline $\begin{array}{l}\text { Hemoglobin AIC, \%, } \\
\text { mean } \pm \mathrm{SD}\end{array}$ & $5.5 \pm 0.5$ & $5.8 \pm 0.7$ \\
\hline $\begin{array}{l}\text { Triglyceride, mg/dl, } \\
\text { mean } \pm \mathrm{SD}\end{array}$ & $|45.8 \pm 5| .9$ & $149.8 \pm 50.7$ \\
\hline $\begin{array}{l}\text { Low density } \\
\text { lipoprotein, } \mathrm{mg} / \mathrm{dl} \text {, } \\
\text { mean } \pm \mathrm{SD}\end{array}$ & $96.8 \pm 27.8$ & $97.1 \pm 30.6$ \\
\hline $\begin{array}{l}\text { High density } \\
\text { lipoprotein, mg/dl, } \\
\text { mean } \pm \mathrm{SD}\end{array}$ & $51.7 \pm 21.4$ & $49.5 \pm 20.6$ \\
\hline
\end{tabular}

Abbreviations: $n$, number; SD, standard deviation. 
(Table 2). Using the same test, the pioglitazone group showed significantly greater score reduction from baseline to week 2 (Cohen's $d=1.33,95 \% \mathrm{CI}=0.62$ to 1.99 ), and to week 6 (Cohen's $d=0.77,95 \% \mathrm{CI}=0.12$ to 1.41 ), compared with the placebo group. However, score change between the second and sixth week was not different between the two groups (Cohen's $d=0.17,95 \% \mathrm{CI}=-0.45$ to 0.79 ) (Table 2 ).

Supporting ANCOVA results, two-factor ANOVA with repeated measures showed significantly better results in patients in the pioglitazone group than those in the placebo group $(\mathrm{F}(1,38)=9.483, p=0.004)$ (Figures 1 and 2 ). Using Greenhouse-Geisser correction, the effect was also significant for time $(\mathrm{F}(1.580,60.050)=294.393, p<0.001)$ and time-treatment interaction $(\mathrm{F}(1.580,60.050)=7.116$, $p=0.003)$.
Fisher's exact test showed significantly higher frequency of early improvement (at least $20 \%$ reduction in Ham-D score in the first 2 weeks) in the pioglitazone group than in the placebo group (95\% in the pioglitazone group vs $30 \%$ in the placebo group, $p<0.001$ ) (Table 3 ). Patients in the pioglitazone group also showed significantly better response to treatment (at least 50\% reduction in the score) by the fourth and the sixth week (Table 3). Three patients $(15 \%)$ in the placebo group and nine patients $(45 \%)$ in the pioglitazone group achieved remission (Ham-D score $\leqslant 7$ ) by week $6(p=0.04)$ (Table 3$)$.

\section{Adverse Events}

None of the patients in the pioglitazone group experienced edema, cardiorespiratory symptoms, or hepatic abnormalities.

Table 2 Comparison of Scores and Score Changes Between the Two Groups Using Analysis of Covariance

\begin{tabular}{|c|c|c|c|c|c|}
\hline Ham-D score & $\begin{array}{l}\text { Pioglitazone group } \\
\text { mean }(95 \% \mathrm{CI})\end{array}$ & $\begin{array}{l}\text { Placebo group } \\
\text { mean }(95 \% \mathrm{Cl})\end{array}$ & $\begin{array}{c}\text { Mean difference } \\
\text { pioglitazone-placebo }(95 \% \mathrm{CI})\end{array}$ & $\mathbf{F}(1,37)$ & P-value \\
\hline Week 2 & 16.6 (| 5.4 to 17.8$)$ & 20.1 (19.3 to 21.8$)$ & $-3.9(-5.6$ to -2.2$)$ & 21.32 & $<0.001$ \\
\hline Week 4 & 12.0 (10.5 to 13.4$)$ & 15.8 (|4.3 to 17.3$)$ & $-3.8(-5.9$ to -1.7$)$ & 13.53 & 0.001 \\
\hline Week 6 & $8.6(7.1$ to 10.2$)$ & 12.0 (10.5 to 13.6$)$ & $-3.4(-5.6$ to -1.2$)$ & 9.60 & 0.004 \\
\hline Change from baseline to week 2 & $-8.7(-10.0$ to -7.5$)$ & $-4.8(-6.0$ to -3.6$)$ & $-3.9(-5.6$ to -2.2$)$ & 21.32 & $<0.001$ \\
\hline Change from baseline to week 6 & $-16.7(-18.3$ to -15.2$)$ & $-13.4(-\mid 4.9$ to -|| $.8)$ & $-3.4(-5.6$ to -1.2$)$ & 9.60 & 0.005 \\
\hline Change from week 2 to week 6 & $-8.4(-9.8$ to -7.0$)$ & $-8.5(-9.7$ to -7.4$)$ & $0.2(-1.8$ to 2.3$)$ & 0.30 & $0.87 \mid$ \\
\hline
\end{tabular}

Abbreviations: Ham-D, Hamilton Depression Rating Scale; 95\% Cl, 95\% confidence interval.

Mean of each group represents the mean after adjusting for baseline score.

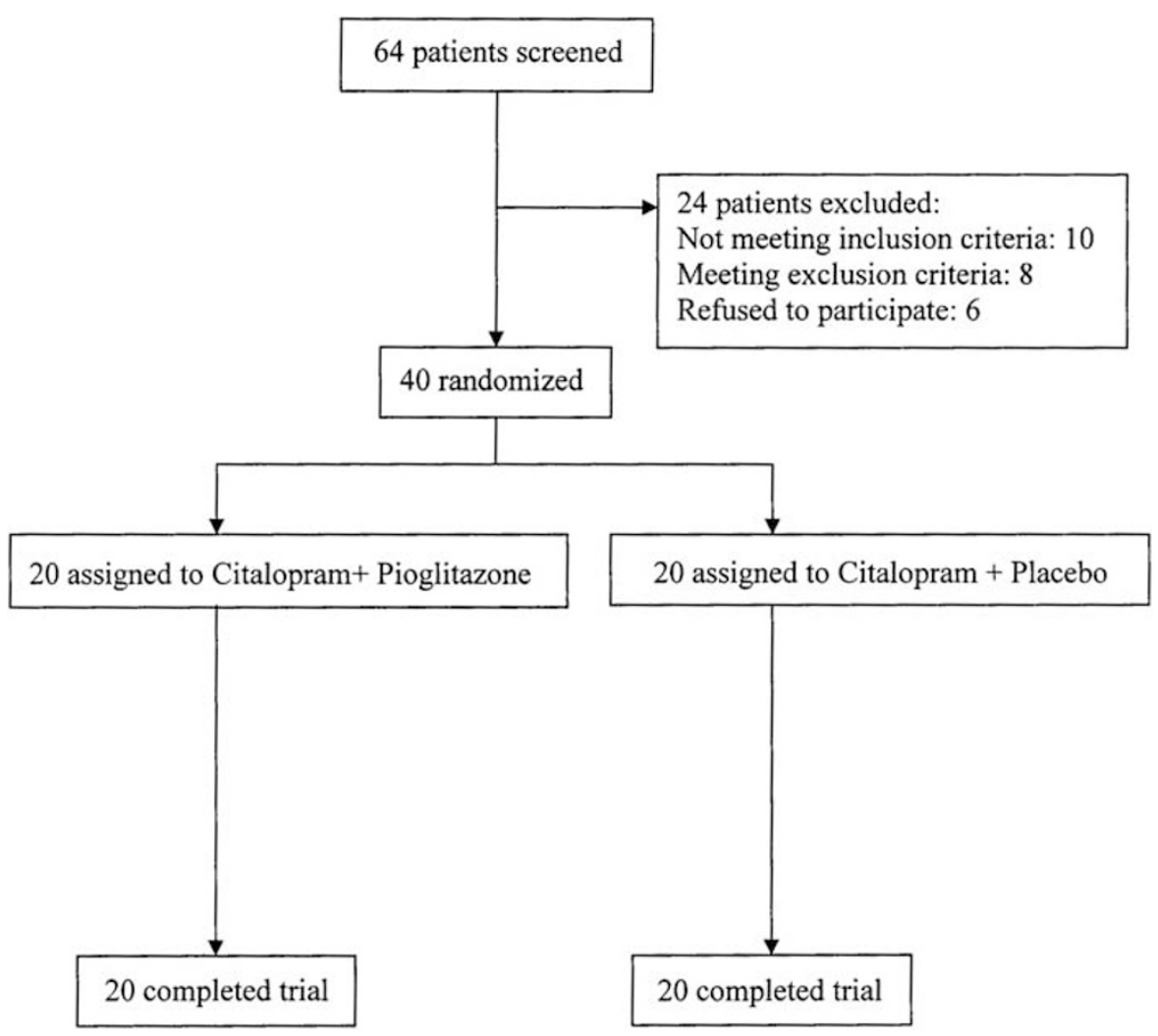

Figure I Flow diagram of the trial. 
Over the period of the trial, 12 side effects were recorded, the most common of which was sexual dysfunction (22.5\%). There was no significant difference in weight change from the baseline in week 6 between the two groups (pioglitazone group at sixth week: $70.25 \pm 7.53 \mathrm{~kg}$, change from the baseline $=-0.05 \pm 0.60 \mathrm{~kg}$; placebo at sixth week: $68.85 \pm 9.57 \mathrm{~kg}$, change from the baseline $=0.15 \pm 0.37 \mathrm{~kg}$; $p$-value for the difference of weight changes between the two groups $=0.213$ ). The frequency of side effects did not differ between the two groups (Table 4). None of the patients in either group showed a significant weight gain ( $7 \%$ or more increase in weight) at the end of the study.

\section{DISCUSSION}

To the best of our knowledge, this was the first randomized controlled trial that evaluated the role of pioglitazone in patients with MDD without any significant metabolic problems. Our study showed that pioglitazone is an effective and safe adjunct to citalopram in patients with moderate-tosevere MDD.

All previously published human studies on this topic have addressed the role of TZDs in patients with concomitant MDD and metabolic syndrome or diabetes. There are two published pilot, open-label studies addressing the role of rosiglitazone and pioglitazone in patients with MDD and

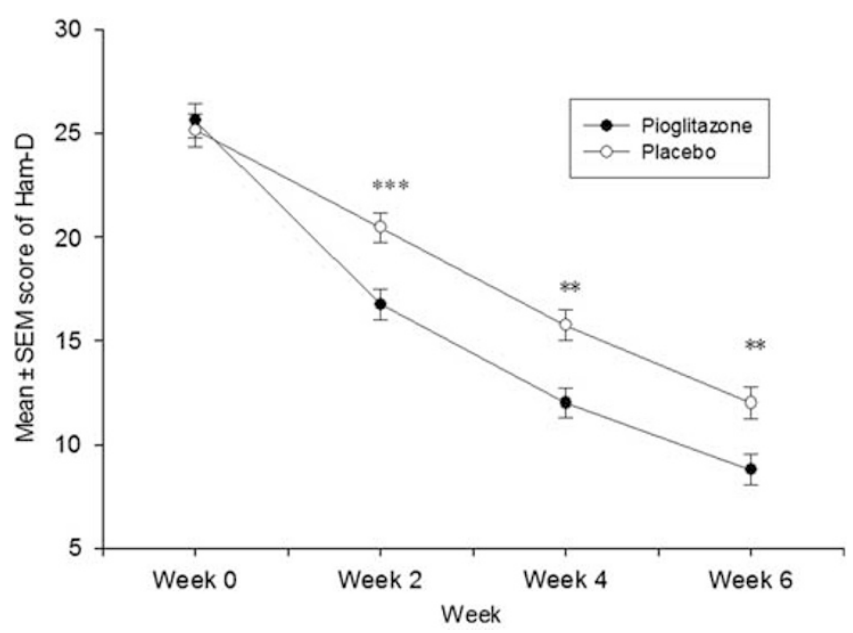

Figure 2 Results of two-factor repeated measure ANOVA for comparison of Hamilton depression rating scale scores (mean \pm SEM) over time between the pioglitazone and placebo groups. ${ }^{*} * P<0.0$ I, ${ }^{*} * * P<0.001$. insulin resistance or metabolic syndrome, respectively (Rasgon et al, 2010; Kemp et al, 2012). Both of these studies showed a decrease in depressive symptoms along with the improvement of metabolic biomarkers. A part of the antidepressant effect of pioglitazone is likely to come from its insulin-sensitizing effect. This statement might be further supported by studies that have shown beneficial augmentative effect of exercise (which have insulin-sensitizing activity) on MDD (Trivedi et al, 2006a; Trivedi et al, 2011). The present study provided substantial evidence of the efficacy of pioglitazone in patients with MDD even when it was not accompanied by metabolic disturbances as evidenced by baseline data of the patients. Although findings of the present study do not rule out the involvement of the insulin-sensitizing effect of pioglitazone in its antidepressant activity, it might also reflect other roles of PPAR-gamma receptor in the CNS. This notion is particularly strengthened by evidence of effects of PPAR-gamma agonists on other neuropsychiatric disorders such as autism and multiple sclerosis, in which inflammation has an important role (Miller et al, 2011; Kaiser et al, 2009). PPAR-gamma agonists act as important neuroprotective, anti-inflammatory, antioxidative, and anti-excitotoxic agents (Garcia-Bueno et al, 2010). They have interactions with several important inflammatory, metabolic, and neurotrophic growth factors

Table 4 Frequency of Side Effects in the Study Groups

\begin{tabular}{|c|c|c|c|}
\hline Side effects & $\begin{array}{l}\text { Citalopram plus } \\
\text { Pioglitazone: } \boldsymbol{n}(\%)\end{array}$ & $\begin{array}{l}\text { Citalopram plus } \\
\text { Placebo: } \boldsymbol{n}(\%)\end{array}$ & $\begin{array}{c}P \\
\text { value }\end{array}$ \\
\hline Anxiety & $3(15 \%)$ & $2(10 \%)$ & 1.00 \\
\hline $\begin{array}{l}\text { Decreased } \\
\text { appetite }\end{array}$ & | (5\%) & $2(1 \%)$ & 1.00 \\
\hline $\begin{array}{l}\text { Increased } \\
\text { appetite }\end{array}$ & $3(15 \%)$ & | (5\%) & 0.60 \\
\hline $\begin{array}{l}\text { Sexual } \\
\text { dysfunction }\end{array}$ & $4(20 \%)$ & $5(25 \%)$ & 1.00 \\
\hline Muscle aches & $3(15 \%)$ & | (5\%) & 0.60 \\
\hline Nausea & $4(20 \%)$ & $3(15 \%)$ & 1.00 \\
\hline Headache & $3(5 \%)$ & | (5\%) & 0.60 \\
\hline Sweating & $2(10 \%)$ & $2(10 \%)$ & 1.00 \\
\hline Stomach ache & $4(20 \%)$ & | (5\%) & 0.34 \\
\hline Insomnia & $2(10 \%)$ & $4(20 \%)$ & 0.66 \\
\hline Sore throat & $2(10 \%)$ & 0 & 0.48 \\
\hline Yawning & I (5\%) & | (5\%) & 1.00 \\
\hline
\end{tabular}

Table 3 Comparison of Outcome Indexes Between the Two Groups

\begin{tabular}{lccrr}
\hline Outcome & Pioglitazone $(\boldsymbol{n}=\mathbf{2 0})$ & Placebo $(\mathbf{n}=\mathbf{2 0})$ & P-value of Fisher's exact test & Risk ratio (95\% Cl) \\
\hline Number (\%) of early improvers & $19(95 \%)$ & $6(30 \%)$ & $<0.001$ & $0.257(0.126$ to 0.523$)$ \\
Number (\%) of remitters & $9(45 \%)$ & $3(15 \%)$ & 0.04 & $0.412(0.148$ to 1.147$)$ \\
Number (\%) of responders at week 4 & $14(70 \%)$ & $5(25 \%)$ & 0.01 & $0.368(0.166$ to 0.820$)$ \\
Number (\%) of responders at week 6 & $19(95 \%)$ & $8(40 \%)$ & $<0.001$ & $0.109(0.016$ to 0.730$)$
\end{tabular}

Early improvement: at least 20\% decrease in Hamilton depression rating scale (Ham-D) score by week 2.

Response: at least $50 \%$ decrease in Ham-D score.

Remission: Ham-D score of 7 or less. 
in the brain (Garcia-Bueno et al, 2010). Prevention of stressinduced rise in iNOS activity, inhibition of nuclear factor kappa B, and prevention of expression of TNF- $\alpha$ in an animal model of stress and neuronal inflammation are components of the elucidated actions of these drugs, which might be linked with pathophysiology of MDD (Munhoz et al, 2008). PPAR-gamma receptor activation might be a mechanism through which anti-inflammatory drugs exert their effect on inflammatory CNS disorders (Heneka and Landreth, 2007). In one study for example, PPAR-gamma agonists could prevent COX-2 in LPS-stimulated microglia and neurons (Kim et al, 2002). The antidepressant effect of COX-2 inhibition by celecoxib has been shown in several clinical trials (Akhondzadeh et al, 2009; Muller et al, 2006; Chen et al, 2010). Another possible explanation of the antidepressant effect of pioglitazone is its inhibitory effect on the glycogen synthase kinase (GSK)-3 $\beta$ pathway and its stimulatory effect on beta-catenin (Ponce-Lopez et al, 2011; Budni et al, 2011). Higher levels of active GSK-3 $\beta$ in the ventral prefrontal cortex is associated with lifetime risk of MDD, whereas beta catenin activity decreases in patients with MDD (Karege et al, 2012). Importantly, impaired neuronal response to stress and neurotransmission, circadian rhythm impairments, neuroinflammation, and immune system dysfunction, all of which might be seen in MDD, are strongly controlled by GSK-3 $\beta$ (Jope, 2011).

One important finding in our study was the significantly higher number of early improved patients (95\%) in the pioglitazone group than in the placebo $(30 \%)$ group. Some large-scale studies have shown that early improvement (defined as $20 \%$ reduction in the depression score within 2 weeks) can sensitively predict better response and higher remission rates (Kim et al, 2011). On the contrary, the absence of early improvement with a high negative predictive value indicates the absence of sustained response after week 4 (Henkel et al, 2009; van Calker et al, 2009). In our study, this was supported by significantly higher response rates at week $4(70 \%)$ and week $6(95 \%)$ and remission rate at week $6(45 \%)$ in the pioglitazone group than in the placebo group. It is noteworthy that a $95 \%$ response rate in the pioglitazone group is higher than that reported in most published studies on drug trials of MDD (Joyce et al, 2002; Apler, 2011; Maes et al, 1999; Fava and Rush, 2006; Trivedi et al, 2006b; Warden et al, 2007; Marcus et al, 2008).

Although pioglitazone caused a rapid reduction in the Ham-D scores in the first 2 weeks and the difference between the two groups remained highly significant until the end of the trial, this additional symptom-reducing effect was not seen in subsequent weeks. This pattern of pioglitazone augmentation of citalopram resembles that of aripiprazole augmentation of antidepressants in a large study of more than 350 patients. In that study, aripiprazole led to a rapid reduction of depression score in the first 2 weeks, after which there was no more score reduction in the aripiprazole-augmented group compared with the nonaugmented group (Marcus et al, 2008). Whereas the mechanism of this rapid effect remains to be established, this characteristic of pioglitazone is a key factor in reaching response and remission in patients with MDD.

Augmentation strategies frequently address treatmentresistant MDD. However, a new line of thought has suggested combination therapy from initiation of antidepressant treatment to improve response and remission rates. This is supported by some (Blier et al, 2009; Blier et al, 2010; Nelson et al, 2004) but not all studies (Rush et al, 2011). Three 6-week studies have compared antidepressant efficacy of the combination therapy with that of monotherapy. Response rate of patients to citalopram monotherapy in our study $(40 \%)$ is comparable to the reported response rates of $43-54 \%$ for mono-therapy in the mentioned studies (Nelson et al, 2004; Blier et al, 2009; Blier et al, 2010). The remission rate of $15 \%$ in the citalopram group in our study is also comparable to the $7-26 \%$ remission rates by week 6 in the above-mentioned studies. The remission rate in our combination therapy group (45\%) was also comparable to that of previous studies (43-58\%). Greater severity of MDD in our study compared with previous studies might explain why the response rate $(95 \%)$ was much more than that of previous studies $(61-76 \%)$, whereas the remission $(\mathrm{Ham}-\mathrm{D}<7)$ rate in our combination therapy group was similar to that in previous studies (Blier et al, 2009; Blier et al, 2010; Nelson et al, 2004).

Frequency of adverse events did not show significant difference between the two groups. Results of several small studies have shown good tolerability of TZDs in patients with neuropsychiatric diseases (Miller et al, 2011; Kaiser et al, 2009; Geldmacher et al, 2011). Among antihypoglycemic drugs, hypoglycemia is particularly rare with pioglitazone and is often limited to diabetic patients who are on combination therapy (Vlckova et al, 2010). Edema (a well-known side effect of pioglitazone) was not seen in our study, which might be because of the shorter duration of treatment, smaller sample size, and the smaller dosage $(30 \mathrm{mg})$ than most studies. In addition, in a recent metaanalysis, pioglitazone mono-therapy was not associated with increased odds of edema (Berlie et al, 2007). Furthermore, short-term use of pioglitazone was not associated with weight gain, which is a common side effect with the routine use of this drug. Nevertheless, larger safety studies in nondiabetic patients who take TZDs are required to reach a meaningful conclusion.

Our study was the first double-blind placebo-controlled study addressing the efficacy of pioglitazone in MDD. In addition, it was the first study (to our knowledge) that evaluated the role of pioglitazone in MDD unaccompanied by diabetes and metabolic syndrome. Nevertheless, it had some limitations. Although our study design was capable of detecting clinically significant differences between the two groups, it was not planned for and thus limited in interpretation of safety issues. Small sample size and short follow-up duration prevented us from assessing the longterm effects of pioglitazone in these patients. In addition, pioglitazone was used as a fixed-dose preparation, which might not be the case in everyday clinical practice. Moreover, metabolic biomarkers were not tested during the study. Thus, the present study was also limited in assessment of metabolic action of pioglitazone in healthy patients with MDD.

In summary, we showed that pioglitazone is an effective and safe short-term adjunctive modality in nondiabetic patients with MDD. In particular, pioglitazone is associated with high rate of early improvement, and thus 
response and remission, which makes this drug a potentially useful augmentative strategy in patients with moderate-to-severe MDD.

\section{ACKNOWLEDGEMENTS}

This study was Dr Khatereh Sepanjnia's postgraduate thesis toward qualification for the Iranian Board of Psychiatry under the supervision of Prof. Shahin Akhondzadeh. This study was supported by a grant from Tehran University of Medical Sciences to Prof. Shahin Akhondzadeh (Grant No. 9476).

\section{DISCLOSURE}

The authors declare no conflict of interest.

\section{REFERENCES}

Abolfazli R, Hosseini M, Ghanizadeh A, Ghaleiha A, Tabrizi M, Raznahan $\mathrm{M}$ et al (2011). Double-blind randomized parallelgroup clinical trial of efficacy of the combination fluoxetine plus modafinil versus fluoxetine plus placebo in the treatment of major depression. Depress Anxiety 28: 297-302.

Akhondzadeh S, Jafari S, Raisi F, Nasehi AA, Ghoreishi A, Salehi B et al (2009). Clinical trial of adjunctive celecoxib treatment in patients with major depression: a double blind and placebo controlled trial. Depress Anxiety 26: 607-611.

Apler A (2011). Citalopram for major depressive disorder in adults: a systematic review and meta-analysis of published placebo-controlled trials. BMJ Open 1: e000106.

Berlie HD, Kalus JS, Jaber LA (2007). Thiazolidinediones and the risk of edema: a meta-analysis. Diabetes Res Clin Pract 76: 279-289.

Blier P, Gobbi G, Turcotte JE, De Montigny C, Boucher N, Hebert C et al (2009). Mirtazapine and paroxetine in major depression: a comparison of mono-therapy versus their combination from treatment initiation. Eur Neuropsychopharmacol 19: 457-465.

Blier P, Ward HE, Tremblay P, Laberge L, Hebert C, Bergeron R (2010). Combination of antidepressant medications from treatment initiation for major depressive disorder: a double-blind randomized study. Am J Psychiatry 167: 281-288.

Budni J, Lobato KR, Binfare RW, Freitas AE, Costa AP, Saavedra $\mathrm{MD}$ et al (2011). Involvement of PI3K, GSK-3beta and PPARgamma in the antidepressant-like effect of folic acid in the forced swimming test in mice. J Psychopharmacol (in press).

Chen CY, Tzeng NS, Chen YC (2010). Maintenance therapy of celecoxib for major depression with mimicking neuropsychological dysfunction. Gen Hosp Psychiatry 32: 647 e7-9.

Eissa Ahmed AA, Al-Rasheed NM (2009). Antidepressant-like effects of rosiglitazone, a PPARgamma agonist, in the rat forced swim and mouse tail suspension tests. Behav Pharmacol 20: 635-642.

Fava M, Rush AJ (2006). Current status of augmentation and combination treatments for major depressive disorder: a literature review and a proposal for a novel approach to improve practice. Psychother Psychosom 75: 139-153.

Garcia-Bueno B, Caso JR, Perez-Nievas BG, Lorenzo P, Leza JC (2007). Effects of peroxisome proliferator-activated receptor gamma agonists on brain glucose and glutamate transporters after stress in rats. Neuropsychopharmacology 32: 1251-1260.

Garcia-Bueno B, Madrigal JL, Lizasoain I, Moro MA, Lorenzo P, Leza JC (2005). The anti-inflammatory prostaglandin 15d-PGJ2 decreases oxidative/nitrosative mediators in brain after acute stress in rats. Psychopharmacology (Berl) 180: 513-522.
Garcia-Bueno B, Perez-Nievas BG, Leza JC (2010). Is there a role for the nuclear receptor PPARgamma in neuropsychiatric diseases? Int J Neuropsychopharmacol 13: 1411-1429.

Geldmacher DS, Fritsch T, Mcclendon MJ, Landreth G (2011). A randomized pilot clinical trial of the safety of pioglitazone in treatment of patients with Alzheimer disease. Arch Neurol 68: 45-50.

Heneka MT, Landreth GE (2007). PPARs in the brain. Biochim Biophys Acta 1771: 1031-1045.

Henkel V, Seemuller F, Obermeier M, Adli M, Bauer M, Mundt C et al (2009). Does early improvement triggered by antidepressants predict response/remission? Analysis of data from a naturalistic study on a large sample of inpatients with major depression. J Affect Disord 115: 439-449.

Jeong EA, Jeon BT, Shin HJ, Kim N, Lee DH, Kim HJ et al (2011). Ketogenic diet-induced peroxisome proliferator-activated receptorgamma activation decreases neuroinflammation in the mouse hippocampus after kainic acid-induced seizures. Exp Neurol 232: 195-202.

Jope RS (2011). Glycogen synthase kinase-3 in the etiology and treatment of mood disorders. Front Mol Neurosci 4: 16.

Joyce PR, Mulder RT, Luty SE, Sullivan PF, Mckenzie JM, Abbott $\mathrm{RM}$ et al (2002). Patterns and predictors of remission, response and recovery in major depression treated with fluoxetine or nortriptyline. Aust N Z J Psychiatry 36: 384-391.

Kaiser CC, Shukla DK, Stebbins GT, Skias DD, Jeffery DR, Stefoski $\mathrm{D}$ et al (2009). A pilot test of pioglitazone as an add-on in patients with relapsing remitting multiple sclerosis. J Neuroimmunol 211: 124-130.

Karege F, Perroud N, Burkhardt S, Fernandez R, Ballmann E, La Harpe R et al (2012). Protein levels of beta-catenin and activation state of glycogen synthase kinase-3beta in major depression. A study with postmortem prefrontal cortex. $J$ Affect Disord 136: 185-188.

Kemp DE, Ismail-Beigi F, Calabrese JR (2009). Antidepressant response associated with pioglitazone: support for an overlapping pathophysiology between major depression and metabolic syndrome. Am J Psychiatry 166: 619.

Kemp DE, Ismail-Beigi F, Ganocy SJ, Conroy C, Gao K, Obral S et al (2012). Use of insulin sensitizers for the treatment of major depressive disorder: a pilot study of pioglitazone for major depression accompanied by abdominal obesity. J Affect Disord 136: $1164-1173$.

Kim EJ, Kwon KJ, Park JY, Lee SH, Moon CH, Baik EJ (2002). Effects of peroxisome proliferator-activated receptor agonists on LPS-induced neuronal death in mixed cortical neurons: associated with iNOS and COX-2. Brain Res 941: 1-10.

Kim JM, Kim SY, Stewart R, Yoo JA, Bae KY, Jung SW et al (2011). Improvement within 2 weeks and later treatment outcomes in patients with depressive disorders: the CRESCEND study. J Affect Disord 129: 183-190.

Maes M, Libbrecht I, Van Hunsel F, Campens D, Meltzer HY (1999). Pindolol and mianserin augment the antidepressant activity of fluoxetine in hospitalized major depressed patients, including those with treatment resistance. J Clin Psychopharmacol 19: 177-182.

Marcus RN, Mcquade RD, Carson WH, Hennicken D, Fava M, Simon JS et al (2008). The efficacy and safety of aripiprazole as adjunctive therapy in major depressive disorder: a second multicenter, randomized, double-blind, placebo-controlled study. J Clin Psychopharmacol 28: 156-165.

Miller BW, Willett KC, Desilets AR (2011). Rosiglitazone and pioglitazone for the treatment of Alzheimer's disease. Ann Pharmacother 45: 1416-1424.

Muller N, Schwarz MJ, Dehning S, Douhe A, Cerovecki A, Goldstein-Muller B et al (2006). The cyclooxygenase-2 inhibitor celecoxib has therapeutic effects in major depression: results of a double-blind, randomized, placebo controlled, add-on pilot study to reboxetine. Mol Psychiatry 11: 680-684. 
Munhoz CD, Garcia-Bueno B, Madrigal JL, Lepsch LB, Scavone C, Leza JC (2008). Stress-induced neuroinflammation: mechanisms and new pharmacological targets. Braz J Med Biol Res 41: 1037-1046.

Nelson JC, Mazure CM, Jatlow PI, Bowers Jr MB, Price LH (2004). Combining norepinephrine and serotonin reuptake inhibition mechanisms for treatment of depression: a double-blind, randomized study. Biol Psychiatry 55: 296-300.

Ponce-Lopez T, Liy-Salmeron G, Hong E, Meneses A (2011). Lithium, phenserine, memantine and pioglitazone reverse memory deficit and restore phospho-GSK3beta decreased in hippocampus in intracerebroventricular streptozotocin induced memory deficit model. Brain Res 1426: 73-85.

Rasgon NL, Kenna HA, Williams KE, Powers B, Wroolie T, Schatzberg AF (2010). Rosiglitazone add-on in treatment of depressed patients with insulin resistance: a pilot study. ScientificWorld J 10: 321-328.

Rosa AO, Kaster MP, Binfare RW, Morales S, Martin-Aparicio E, Navarro-Rico ML et al (2008). Antidepressant-like effect of the novel thiadiazolidinone NP031115 in mice. Prog Neuropsychopharmacol Biol Psychiatry 32: 1549-1556.

Rush AJ, Trivedi MH, Stewart JW, Nierenberg AA, Fava M, Kurian BT et al (2011). Combining medications to enhance depression outcomes (CO-MED): acute and long-term outcomes of a single-blind randomized study. Am J Psychiatry 168: 689-701.

Sadaghiani MS, Javadi-Paydar M, Gharedaghi MH, Fard YY, Dehpour AR (2011). Antidepressant-like effect of pioglitazone in the forced swimming test in mice: the role of PPAR-gamma receptor and nitric oxide pathway. Behav Brain Res 224: 336-343.
Schatzberg AF (2008). Achieving remission and favorable outcomes in patients with depression/anxiety and substance use disorders. CNS Spectr 13: 10-12.

Spiegelman BM (1998). PPAR-gamma: adipogenic regulator and thiazolidinedione receptor. Diabetes 47: 507-514.

Toyomoto M, Ohta M, Okumura K, Yano H, Matsumoto K, Inoue S et al (2004). Prostaglandins are powerful inducers of NGF and BDNF production in mouse astrocyte cultures. FEBS Lett 562: 211-215.

Trivedi MH, Greer TL, Church TS, Carmody TJ, Grannemann BD, Galper DI et al (2011). Exercise as an augmentation treatment for nonremitted major depressive disorder: a randomized, parallel dose comparison. J Clin Psychiatry 72: 677-684.

Trivedi MH, Greer TL, Grannemann BD, Chambliss HO, Jordan AN (2006a). Exercise as an augmentation strategy for treatment of major depression. J Psychiatr Pract 12: 205-213.

Trivedi MH, Rush AJ, Wisniewski SR, Nierenberg AA, Warden D, Ritz L et al (2006b). Evaluation of outcomes with citalopram for depression using measurement-based care in $\mathrm{STAR}^{\star} \mathrm{D}$ : implications for clinical practice. Am J Psychiatry 163: 28-40.

Van Calker D, Zobel I, Dykierek P, Deimel CM, Kech S, Lieb K et al (2009). Time course of response to antidepressants: predictive value of early improvement and effect of additional psychotherapy. J Affect Disord 114: 243-253.

Vlckova V, Cornelius V, Kasliwal R, Wilton L, Shakir S (2010). Hypoglycaemia with pioglitazone: analysis of data from the Prescription-Event Monitoring study. J Eval Clin Pract 16: $1124-1128$.

Warden D, Rush AJ, Trivedi MH, Fava M, Wisniewski SR (2007). The STAR ${ }^{\star} \mathrm{D}$ Project results: a comprehensive review of findings. Curr Psychiatry Rep 9: 449-459. 